\title{
The Role of Gender and Physical Performance on Injuries: An Army Study
}

Morgan K. Anderson, MPH, Tyson Grier, MS, Esther O. Dada, MPH, Michelle Canham-

Chervak, PhD, Bruce H. Jones, MD, MPH

From the Injury Prevention Program, Epidemiology and Disease Portfolio, Army Public Health Center, Aberdeen Proving Grounds, Maryland

Address correspondence to: Morgan K. Anderson, MPH, Army Public Health Center, Building E1570, 5158 Blackhawk Road, Aberdeen Proving Ground MD 21010. E-mail: morgan.k.anderson.ctr@mail.mil. 
Introduction: In basic combat training, women experience twice as many injuries as men; however, evidence at the operational Army level is limited. This study aims to investigate the association between gender and injury likelihood while controlling for certain confounding factors in the operational Army.

Methods: Data were analyzed in 2015 from a cross-sectional study utilizing data from a 20102011 survey of light infantry Army Soldiers. Gender, age, body fat, tobacco use, Army Physical Fitness Test (2-mile run, push-ups, and sit-ups), occupational physical demand, and injury data were obtained via paper survey. ORs and 95\% CIs from a multivariable analysis were calculated. Results: Surveys were completed by 4,384 male and 363 female Soldiers. Injury incidence was $42 \%$ for men and $53 \%$ for women. After adjusting for the aforementioned variables, injury likelihood was higher in Soldiers aged $\geq 27$ years (OR [age $27-29 / 22-26$ years] $=1.26,95 \%$ $\mathrm{CI}=1.07,1.48 ;$ OR $[$ age $\geq 30 / 22-26$ years $]=1.28,95 \% \mathrm{CI}=1.08,1.51)$, Soldiers with body fat $\geq 23.38 \%$ (OR [body fat $\geq 23.38 \% / \leq 19.28 \%]=1.30,95 \% \mathrm{CI}=1.08,1.57$ ), and Soldiers with the slowest 2 -mile run times $(\mathrm{OR}[\geq 15.68 / \leq 14.13$ minutes $]=1.53,95 \% \mathrm{CI}=1.26,1.85)$. Women were no more likely than men to sustain an injury.

Conclusions: When accounting for age, body fat, physical performance, and occupational physical demand, there was no gender difference in the likelihood of injury among Soldiers. Although women, on average, have lower aerobic and muscular performance than men, results suggest men and women of similar physical performance experience similar injury likelihood. 


\section{INTRODUCTION}

With the U.S. Army's proposed plan to reduce its population by 40,000 Soldiers by 2018 , it is critically important to ensure an optimal level of military readiness. ${ }^{1}$ This can be accomplished by addressing several factors, including fitness and injury. Even though women make up a small portion of the army population (14\%), their involvement and contributions are mission essential. ${ }^{2,3}$ A recent example recognizing women's importance in the military is the opening of combat arms occupations to women. Therefore, it is more important than ever to assess the physical performance and the likelihood of injury between men and women. ${ }^{4}$

Several physical differences exist between men and women related to cardiovascular endurance, muscular strength, and body composition. ${ }^{5-8}$ When comparing maximal oxygen consumption levels, a measure of cardiovascular endurance, aerobically untrained and trained women achieve values approximately $15 \%-30 \%$ lower than men of similar age. ${ }^{5-7}$ Absolute muscular strength has also been shown to be lower, on average, in women compared with men, $50 \%$ lower in upper body strength and $30 \%$ lower in leg strength. ${ }^{8}$ When analyses are adjusted for body mass, differences in strength decreased, but still persisted. ${ }^{8}$ Additionally, essential body fat requirements differ between men and women, with the lowest acceptable limit for healthy men at $3 \%$ body fat versus $12 \%$ for healthy women. ${ }^{8}$

Associations of physical performance, gender, and likelihood of injury have been well documented within basic combat training (BCT) settings. These studies have shown female trainees experience almost twice as many injuries compared with male trainees and that low levels of aerobic performance (measured by 2-mile run time) are associated with injuries in both 
men and women. ${ }^{9-11}$ However, several studies have shown that women and men of the same physical performance level have similar odds of injury during Army BCT. ${ }^{12-14}$ The BCT population on average differs from the operational population at the physical performance level as measured by the Army Physical Fitness Test (APFT). Women's and men's average aerobic and muscular performance scores, as measured by the APFT, are approximately $23 \%-63 \%$ and $17 \%-47 \%$ lower, respectively, at the BCT level compared with the operational population. ${ }^{10,15,16}$ Based on these differences, there may also be differing results in odds of injury and gender at the operational level. The association of gender and odds of injury has not been investigated among Soldiers in operational units. This analysis explores the association between gender and odds of injury in an operational Army infantry brigade while controlling for confounding factors such as age, body fat, tobacco use, physical performance as measured by the APFT, and occupational physical demand.

\section{METHODS}

This retrospective cross-sectional investigation included enlisted Active Duty Soldiers from two Army light infantry brigades located on the same U.S. military installation from 2010 to 2011. Each brigade consisted of armor, special troops, field artillery, infantry, cavalry, and brigade support units. Participating Soldiers completed paper surveys as part of an ongoing physical training program evaluation required by their leadership. Army Public Health Center staff distributed and collected the surveys at the military installation. The surveys were shipped through a tracked package service to Army Public Health Center Injury Prevention and scanned into an electronic format for quality control and analyses. The survey obtained self-reported data on gender, date of birth, height and weight, Military occupations, cigarette smoking, physical 
performance (APFT), and injuries occurring within the last 12 months. Injury was defined as "either accidental or on purpose and occurring when strong sudden forces are applied to the body (traumatic) or smaller forces are applied to the body over and over again (overuse)." Overall injuries (traumatic and overuse) were included in the injury analysis. Age was calculated by subtracting the self-reported date of birth from the date the survey was completed and was categorized using APFT-designated age categories. ${ }^{17} \mathrm{BMI}\left(\mathrm{kg} / \mathrm{m}^{2}\right)$ was calculated from selfreported height and weight. Body fat percentage was indirectly calculated using a body fat prediction equation established by Gallagher et al., ${ }^{18}$ as seen below, where sex $=1$ for male and 0 for female. Body fat percentage results were divided into tertiles (thirds). The prediction error of this equation was low (4.98\%). ${ }^{18}$

$$
\begin{aligned}
& \text { Body fat percentage }=64.5-848 \times(1 / \mathrm{BMI})+0.079 \times \text { age }-16.4 \\
& \quad \times \operatorname{sex}+0.05 \times \operatorname{sex} \times \text { age }+39.0 \times \operatorname{sex} \times(1 / \mathrm{BMI})
\end{aligned}
$$

Cigarette smokers were identified as those who had smoked $\geq 100$ cigarettes in their lifetime and smoked at least one cigarette in the previous 30 days from the survey administration date. This definition of cigarette smokers was established by the Centers for Disease Control and Prevention's Behavioral Risk Factor Surveillance System. Physical performance was measured by self-reported results on the most recent APFT. The APFT consists of a 2-minute maximal effort push-up event, a 2-minute maximal effort sit-up event, and a 2-mile run performed for time. ${ }^{17}$ All three events were completed in accordance with Field Manual 7-22. ${ }^{17}$ APFT results were divided into tertiles (33\%) of highest, moderate, and lowest physical performance. Every entry-level enlisted Military Occupational Specialty is assigned a physical demand level 
necessary to complete occupationally assigned tasks. Occupational physical demand levels are categorized as Very Heavy, Heavy, Moderately Heavy, Medium, and Light as listed in the Department of the Army Pamphlet (DA Pam) 611-21. ${ }^{19}$ Anderson and colleagues ${ }^{16}$ identify the Military Occupational Specialties and physical demand requirements necessary to be categorized in each of the levels listed above.

\section{Statistical Analysis}

Data were analyzed in 2015 using SPSS, version 19.0. Unadjusted risk ratios and 95\% CIs were calculated to assess the association of personal characteristics and physical performance with injury risk for men and women separately. When calculating regression analysis, a reference parameter was selected for each variable that was expected to have the lowest injury risk (e.g., non-smokers, low body fat percentage, younger age), or if none was expected, the lowest injury percentage category was selected. Potential risk factors significant at the $p \leq 0.10$ level in the univariate logistic regression results were entered into a multiple logistic regression model. ORs and $95 \%$ CIs from multivariate analyses were calculated to assess independent factors associated with injury.

\section{RESULTS}

Surveys were voluntarily completed by 4,747 enlisted Soldiers in two brigades $(4,384$ men and 363 women), accounting for $43 \%$ of the population. Soldiers had a mean age of $30.4(\mathrm{SD}=6.0)$ years (men, $30.5[\mathrm{SD}=6.0]$ years; women, $29.9[\mathrm{SD}=6.1]$ years). The average estimated body fat percentage for men was $20.4 \%(\mathrm{SD}=4.6 \%)$ and for women was $31.7 \%(\mathrm{SD}=5.3 \%)$. Forty-three percent of Soldiers reported an injury in the past 12 months (42\% men and 53\% women). 
Figure 1 displays the percentage of enlisted men and women injured by APFT age groups (oldest, moderate, and youngest) and estimated body fat percentage (highest, moderate, and lowest). Men in the oldest age category experienced $8 \%$ more injuries than women, but women in the youngest age group experienced $22 \%$ more injuries than men. Figure 1 also shows the estimated body fat percentage tertile groups varied by almost $12 \%$ between men and women. Women experienced more injuries than men for all three estimated body fat percentage tertiles.

Figure 2 displays the percentage of enlisted men and women injured by APFT events by tertiles (highest, moderate, and lowest). This figure shows a trend between both men and women that as physical performance decreased, injury rates increased. When comparing women with men, women experienced a higher percentage of injuries. This figure also shows the tertile groupings varied greatly between men and women for all three events.

Table 1 shows the unadjusted relative injury risks among enlisted men and women by personal characteristics and physical performance. Categorical APFT scores and body fat percentages presented in this table were based on calculated tertile values from the entire population of men and women combined (gender neutral), rather than the gender-specific tertiles presented in Figure 1. Risk of injury was higher among men aged $\geq 27$ years, with a body fat percentage of $\geq 19.29 \%$, and lowest performance on all APFT events. For women, risk of injury was higher among those with the lowest APFT sit-up performance. Relative to men, women had higher risks of injury among those who were aged $<27$ years and had the poorest APFT push-up and sit-up performances. When comparing physical performance of men and women, $1 \%$ of women 
compared with $31 \%$ of men were in the highest-performing push-up group, $22 \%$ of women versus $27 \%$ of men were in the highest-performance sit-up group, and $3 \%$ of women compared with $29 \%$ of men were in the highest-performing 2-mile run group. Table 2 displays the unadjusted logistic regression results of the association of gender, personal characteristics, physical performance, and injury risk for enlisted Soldiers based on tertiles from the total population of men and women combined. Injury risk was higher among women and those aged $\geq 27$ years, with a body fat percentage of $\geq 19.29 \%$, and with poorer performance on all APFT events.

Table 2 displays multiple logistic regression results of the association of gender, personal characteristics, physical performance, and likelihood of injury for enlisted Soldiers based on tertiles from the total population of men and women combined. Variables entered into the multivariable model included gender, age, body fat percentage, APFT push-ups, APFT sit-ups, and APFT 2-mile run. In this model, likelihood of injury was associated with the following characteristics: age $\geq 27$ years, body fat percentage $\geq 23.4 \%$, poorest sit-up performance, and slowest 2-mile run time performance. Gender did not remain a statistically significant predictor of injury in the multivariable model.

\section{DISCUSSION}

This investigation is a first examination of the effect of gender on likelihood of injury among light infantry Army Soldiers in operational units, while accounting for personal characteristics and physical performance. The main finding was that gender was not an independent factor for injury among operational Army Soldiers when controlling for age, body fat, physical 
performance as measured by APFT, and occupational physical demands. Independent variables associated with injury included older age, higher body fat, lower muscular endurance, and poor aerobic performance. Lower aerobic physical performance had the strongest association with likelihood of injury.

With univariate analyses, female Soldiers in operational units were more likely to experience injuries than male Soldiers. This finding is consistent with prior Army studies in BCT settings where female trainees experienced 1.5-2.3 times more injuries compared with male trainees. ${ }^{9-}$ ${ }^{11,20}$ However, in this investigation, the unadjusted relative injury risk between female and male Soldiers was lower in operational units with women experiencing only 1.26 times more injuries versus men. Although female Soldiers have consistently been shown to have higher injury rates than men, this has been without controlling for physical performance and other variables such as age, body fat, and occupational physical demand. This investigation found that gender was not an independent variable associated with injury in a multivariate model that also accounted for physical performance. This finding substantiates previous BCT studies that reported male and female trainees with similar physical performance levels exhibited similar injury risks. Canham et al. ${ }^{13}$ reported female BCT trainees were at 1.6 times higher risk for injury, but when physical performance was controlled for by stratifying on run time results, the difference in injury risk between male and female trainees was insignificant. A similar study by Jones and colleagues ${ }^{14}$ showed female BCT trainees were at 1.8 times greater risk for injury, but when run time results and body fat were stratified, the injury risk between men and women was no longer significant. In a multivariate analysis, Bell et al. ${ }^{12}$ assessed the association between gender and physical 
training-related injuries, concluding that female gender was not a significant predictor of injury when controlling for demographics, body composition, and physical fitness.

Even though men and women experience similar odds of injury when physical performance levels are comparable, gender should still be considered a variable associated with injury based on inherent physiologic differences. It is well established that on average, women have less aerobic and muscular endurance than men. ${ }^{8}$ Even at elite performance levels, gender gaps exist in world record performances. When comparing male and female world record holders, it has been observed that women lagged behind men in various athletic performances, including an $11 \%$ gap in running performances and a $37 \%$ gap in weight lifting performances. ${ }^{21}$ In this investigation, physical performance groups according to gender-neutral tertiles showed a majority of the women were in the lowest-performing groups with only $1 \%$ and $2 \%$ of the women placing in the top-performing groups for push-ups and 2-mile run times, respectively. Women did have a similar presence to men for sit-ups with $22 \%$ of women in the top performance group compared to $27 \%$ for men. Unlike women, men were more evenly distributed among the three physical performance groups. Therefore, although gender may not be an independent risk factor when controlling for age, body composition, and physical performance, it should be kept in mind that, on average, women's aerobic and muscular physical performance is lower compared with men as noted above. At the military level, it should be standard practice to ensure women and men have the same opportunity to train.

Older Soldiers were observed to have a greater likelihood for injury than younger Soldiers. Older age has been linked to a decline in cardiorespiratory and muscular endurance, which may cause 
greater physiologic stress ${ }^{22}$ and lead to an increase in the likelihood of injury. Previous studies have shown that lower cardiovascular endurance, as measured by 2-mile run time, are associated variables for injury. ${ }^{9,23-25}$ Older Soldiers in the operational Army may also have had more exposure to years of physically demanding training and prior injuries compared with the younger Soldiers, predisposing them to more injuries. In the operational Army, older Soldiers may also be more likely to hold supervisory positions, which may lead to less exposure to injurious situations, but also more-sedentary positions, contributing to lower physical performance levels that can place them at higher odds for injury.

This investigation showed that Soldiers with higher body fat had a greater odds of injury compared with Soldiers with lower body fat. To the best of the authors' knowledge, there have been no prior studies analyzing both men and women's body composition in an operational population. Past BCT studies have shown that higher BMI is associated with injury risk. ${ }^{11,26}$ For example, Jones and colleagues ${ }^{11}$ determined that both male and female Soldiers in the lowest and highest BMI groups had a greater likelihood of experiencing an injury compared with Soldiers in the more "average" BMI group. Higher BMI may lead to greater injury risk due to increased strain on the musculoskeletal system. ${ }^{27}$ Excess weight may contribute to more rapid physiologic fatigue, which is associated with an increased likelihood of injury. Estimating body fat percentage by accounting for age, gender, and BMI measures was used as a more appropriate measure instead of using BMI alone. Women with the same BMI as men have been shown to have $10 \%$ more body fat; therefore, BMI cannot be used to determine the likelihood of injury in this analyses of both men and women. ${ }^{28}$ Even though BMI has been recommended by organizations such as the Centers for Disease Control and Prevention, WHO, and NIH as a good 
screening tool for overweight and obese individuals in large populations, ${ }^{29,30}$ some studies have cautioned against the use of BMI to estimate body fat owing to its validity in young athletic populations. ${ }^{31,32}$ Previous studies have shown correlations between 0.74 and 0.88 for body fat estimations and BMI. ${ }^{18,33,34}$

This investigation, along with several other military studies, has shown that Soldiers with low cardiorespiratory endurance as measured by APFT 2-mile run time experience higher injury rates and risk. ${ }^{9,20,23-26,35}$ Individuals with lower cardiorespiratory endurance may experience greater physiologic strain, which may lead to increased injury risk. ${ }^{36}$ Previous studies have also reported associations between muscular endurance, as measured by the APFT push-ups and sit-ups, and injury risk during BCT. ${ }^{9,17,25}$ Evidence from earlier studies and this current investigation suggest that low fitness in general is a primary risk factor for injury. ${ }^{9-11}$

\section{Limitations}

Data were collected by self-administered surveys, which can be subject to recall bias. However, prior analyses have shown high correlations $(0.71-0.87)$ between self-reported APFT data. ${ }^{37,38}$ Self-reported injuries were broadly defined and the specificity of the severity of injury was not examined in this analysis. This specific light infantry brigade population comprised only $8 \%$ women and the small sample size may have had an impact on the result. However, at the time of the study, combat roles were restricted to male Soldiers. ${ }^{3}$ BMI has been considered to be a fairly reliable indicator of body fat for population-based analyses. ${ }^{39}$ However, some individuals may be misclassified as overweight as defined as BMI ranging from 25 to 29.9 as a result of increased muscularity. Also, Centers for Disease Control and Prevention BMI cut points might not be 
appropriate for all ethnic groups given evidence showing associations between BMI, body fat percentage, and distribution of body fat may differ among ethnic groups. ${ }^{40}$

\section{CONCLUSIONS}

This analysis investigated the association of gender and injury, while accounting for personal characteristics and physical performance. When accounting for age, body fat, occupational physical demand, and physical performance, as measured by APFT performance, there was no difference in the likelihood of injury between men and women. Low aerobic physical performance appears to be a primary factor associated with injury. This suggests that men and women with similar physical performance levels experience similar likelihood of injury. Injury prevention efforts in military populations and other young, physically active populations should target improvements in overall physical fitness, particularly aerobic fitness, especially for female Soldiers. Similarly, when considering future Military Occupational Specialty entry requirements, military leadership should emphasis physical capabilities rather than gender. 


\section{ACKNOWLEDGMENTS}

The views expressed in this article are those of the author(s) and do not necessarily reflect the official policy of the Department of Defense, Department of the Army, U.S. Army Medical Department, or the U.S. Government.

This project used a previously anonymized database and was determined to be public health practice by the Army Public Health Center Public Health Review Board.

No financial disclosures were reported by the authors of this paper. 


\section{REFERENCES}

1. Lamonthe D. Army details how it will cut to its smallest size since before World War 2 . The Washington Post. July 9, 2015. www.washingtonpost.com/news/checkpoint/wp/2015/07/09/army-details-how-it-will-cutto-its-smallest-size-since-before-world-war-ii/. Accessed August 30, 2015.

2. Statistics on Women in the Military. The Women's Memorial Web site. www.womensmemorial.org/PDFs/StatsonWIM.pdf. Accessed August 8, 2016.

3. Alvarez L. Women at arms: G.I. jane breaks the combat barrier. The New York Times. August 16, 2009. www.nytimes.com/2009/08/16/us/16women.html?ref=womenatarms\&_r=2\&. Accessed August 8, 2016.

4. Bumiller E, Shanker T. Pentagon is set to lift combat ban for women. New York Times. January 23, 2013. www.nytimes.com/2013/01/24/us/pentagon-says-it-is-lifting-ban-onwomen-in-combat.html?_r=0. Accessed August 30, 2015.

5. Bergh U. The influence of body mass in cross-country skiing. Med Sci Sports Exerc. 1987;19(4):324-331. http://dx.doi.org/10.1249/00005768-198708000-00002.

6. Sharp MA, Patton JF, Knapik JJ, et al. Comparison of the physical fitness of men and women entering the U.S. Army: 1978-1998. Med Sci Sports Exerc. 2002;34(2):356-363. http://dx.doi.org/10.1097/00005768-200202000-00026.

7. Vogel JA, Patton JF, Mellow RP, Daniels WL. An analysis of aerobic capacity in a large United States population. J Appl Physiol. 1986;60(2):494-500. 
8. McArdle WD, Katch FI, Katch VL. Exercise Physiology: Nutrition, Energy, and Human Performance. 7th ed. Baltimore, MD: Wolters Kluwer Health, 2010.

9. Knapik JJ, Sharp MA, Canham-Chervak M, et al. Risk factors for training-related injuries among men and women in basic combat training. Med Sci Sports Exerc. 2001;33(6):946954. http://dx.doi.org/10.1097/00005768-200106000-00014.

10. Knapik JJ, Swedler DI, Grier TL, et al. Injury reduction effectiveness of selecting running shoes based on plantar shape. J Strength Cond Res. 2009;23(3):685-697. http://dx.doi.org/10.1519/JSC.0b013e3181a0fc63.

11. Jones BH, Bovee MW, Harris JM, Cowan DN. Intrinsic risk factors for exercise-related injuries among male and female Army trainees. Am J Sports Med. 1993;21(5):705-710. http://dx.doi.org/10.1177/036354659302100512.

12. Bell NS, Mangione TW, Hemenway D, Amoroso PJ, Jones BH: High injury rates among female army trainees: a function of gender? Am J Prev Med. 2000;18(3):141-146. http://dx.doi.org/10.1016/S0749-3797(99)00173-7.

13. Canham ML, McFerren MA, Jones BH. The Association of Injury with Physical Fitness Among Men and Women in Gender Integrated Basic Combat Training Units. MSMR. 1996;2:8-10.

14. Jones BH, Bovee MW, Knapik JJ. The association between body composition, physical fitness, and injuries among young men and women in the Army. In: Mariotte BM, Grumstrup-Scott J Editors. Body composition and physical performance. Washington DC, 1992:141-173. 
15. Anderson MK, Grier T, Canham-Chervak M, Bushman TT, Jones BH. Risk Factors associated with higher body fat in U.S. Army female Soldiers. U.S. Army Med Dep J. 2014;April-June:74-82.

16. Anderson MK, Grier T, Canham-Chervak M, Bushman TT, Jones BH. Occupation and other risk factors for injury among enlisted U.S. Army Soldiers. Public Health. 2015;129(5):531-538. http://dx.doi.org/10.1016/j.puhe.2015.02.003.

17. Headquarters Department of the Army. Army physical readiness training: field manual 722: Appendix A; 2012.

18. Gallagher D, Heymsfield S, Heo M, et al. Healthy percentage body fat ranges: an approach for developing guidelines based on body mass index. Am J Clin Nutr. 2000;72(3):694-701.

19. Department of the Army. Military occupational classification and structure. Washington, DC: Pamphlet 611-21; 2009-2012. Department of Defense.

20. Grier T, Morrison S, Knapik JJ, Canham-Chervak M, Jones BH. Risk factors for injuries in the U.S. Army ordnance school. Mil Med. 2011;176(11):1292-1299. http://dx.doi.org/10.7205/MILMED-D-11-00215.

21. Thibault V, Guilaume M, Berthelot G, et al. Women and men in sport performance: The gender gap has not evolved since 1983. J Sports Sci Med. 2010;9(2):214-223.

22. Jones BH, Cowan DN, Tomlinson JP, et al. Epidemiology of injuries associated with physical training among young men in the Army. Med Sci Sports Exerc. 1993;25(2):197203. http://dx.doi.org/10.1249/00005768-199302000-00006. 
23. Knapik JJ, Ang P, Reynolds K, Jones B. Physical Fitness, age, and injury incidence in infantry soldiers. J Occup Med. 1993;35(6):946-954. http://dx.doi.org/10.1097/00043764-199306000-00017.

24. Ruscio BA, Jones BH, Bullock $\mathrm{SH}$, et al. A process to identify military injury prevention priorities based on injury type and limited duty days. Am J Prev Med. 2010;38(1S):S19S33. http://dx.doi.org/10.1016/j.amepre.2009.10.004.

25. Grier T, Chervak M, McNulty V, Jones BH. Extreme conditioning programs and injury risk in a U.S. Army brigade combat team. U.S. Army Med Dep J. 2013;Oct-Dec:36-47. 26. Macera CA, Jackson KL, Hagenmaier GW, et al. Age, physical activity, physical fitness, body composition and incidence of orthopaedic problems. Res $Q$. 1989;60:225-233.

27. Knapik JJ. The importance of physical fitness for injury prevention: Part 2. J Spec Op Med. 2015;15(2):78-81.

28. Jackson AS, Stanforth PR, Gagnon J, et al. The effect of sex, age and race on estimating percentage body fat from body mass index: The Heritage Family Study. Int J Obes Relat Metab Disord. 2002;26(6):789-796.

29. HealthyWeight — It's Not a Diet, It's a Lifestyle Accessed. CDC. www.cdc.gov/healthyweight/assessing/bmi/adult_bmi/index.html. Accessed November 6, 2016.

30. What is Overweight and Obesity? WHO. www.who.int/dietphysicalactivity/childhood_what/en/. Accessed November 8, 2013.

31. Ode J, Pivarnki J, Reeves M, Knous J. Body mass index as a predictor of percent fat in college athletes and nonathletes. Med Sci Sports Exerc. 2007;39(3):403-409. http://dx.doi.org/10.1249/01.mss.0000247008.19127.3e. 
32. Witt K, Bush E. College athletes with an elevated body mass index often have a high upper arm muscle area, but not elevated triceps and subscapular skinfolds. J Am Diet Assoc. 2005;105(4):599-602. http://dx.doi.org/10.1016/j.jada.2005.01.008.

33. Deurenberg P, Westrate J, Seidell J. Body mass index as a measure of body fatness: age and sex specific prediction formulas. Br J Nutr. 1991;65(2):105-114. http://dx.doi.org/10.1079/BJN19910073.

34. Grier T, Canham-Chervak M, Sharp M, Jones BH. Does body mass index misclassify physically active young men. Prev Med Rep. 2015;2:483-487. http://dx.doi.org/10.1016/j.pmedr.2015.06.003.

35. Jones BH, Knapik JJ. Physical training and exercise-related injuries: surveillance, research and injury prevention in military populations. Sports Med. 1999;27(2):111e25.

36. Cooper BL, Arabian JM. Department of defense physical strength and job performance survey: report on the ability of first-term enlisted personnel to perform physically demanding work. Millington, TN: Navy Personnel Research, Studies and Technology Technical Note, No. NPRST-TN-03e4; 2002.

37. Jones SB, Knapik JJ, Sharp MA, Darakjy S, Jones BH. The validity of Self-Reported Physical Fitness Test Scores. Mil Med. 2007;172(2):115-120. http://dx.doi.org/10.7205/MILMED.172.2.115.

38. Martin RC, Grier T, Canham-Chervak M, et al. Validity of Self-Reported Physical Fitness and Body Mass Index in a Military Population. J Strength Cond Res. 2016;30(1):26-32. http://dx.doi.org/10.1519/JSC.0000000000001026.

39. Global Database on Body Mass Index: BMI Classification. WHO; 2004. http://apps.who.int/bmi/index.jsp?introPage=intro_3.html. Accessed August 8, 2016. 
40. CDC. About BMI for Adults. In Healthy Weight - it's not a diet, it's a lifestyle. Division of Nutrition, Physical Activity and Obesity.

www.cdc.gov/healthyweight/assessing/bmi/adult_bmi/index.html. Accessed February 6, 2012. 


\section{LIST OF FIGURES}

Figure 1. Demographics and injury comparison: men and women.

Figure 2. Physical performance and injury comparison: enlisted men and women. 
Table 1. Unadjusted Injury Risks in Army Soldiers by Gender Neutral Tertiles

\begin{tabular}{|c|c|c|c|c|c|c|c|c|}
\hline \multirow[t]{2}{*}{ Variable level } & \multicolumn{4}{|c|}{ Men $(n=4,384)$} & \multicolumn{4}{|c|}{ Women $(n=363)$} \\
\hline & $\mathbf{N}$ & $\%$ Injured & Risk ratio & $p$-value & $\mathbf{N}$ & $\%$ Injured & Risk ratio & $p$-value \\
\hline \multicolumn{9}{|c|}{ Body fat \% (Tertiles) ${ }^{\mathrm{a}}$} \\
\hline$\leq 19.28$ & 1,581 & $36 \%$ & 1.00 & & 10 & $60 \%$ & 1.00 & \\
\hline $19.29-23.37$ & 1,501 & $41 \%$ & $1.15(1.06-1.26)$ & $<0.01$ & 9 & $44 \%$ & $0.74(0.30-1.80)$ & 0.50 \\
\hline$\geq 23.38$ & 1,179 & $50 \%$ & $1.40(1.28-1.52)$ & $<0.01$ & 341 & $53 \%$ & $0.88(0.53-1.47)$ & 0.65 \\
\hline \multicolumn{9}{|c|}{ APFT push-ups (reps) (Tertiles) ${ }^{a}$} \\
\hline$\leq 57$ & 1,239 & $46 \%$ & $1.26(1.15-1.38)$ & $<0.01$ & 302 & $52 \%$ & $1.30(0.44-3.82)$ & 0.59 \\
\hline $58-71$ & 1,433 & $41 \%$ & $1.13(1.03-1.24)$ & 0.01 & 19 & $42 \%$ & $1.05(0.32-3.48)$ & 0.93 \\
\hline$\geq 72$ & 1,348 & $37 \%$ & 1.00 & & 5 & $40 \%$ & 1.00 & \\
\hline \multicolumn{9}{|c|}{ APFT sit-ups (reps) (Tertiles) ${ }^{\mathrm{a}}$} \\
\hline$\leq 62$ & 1,396 & $47 \%$ & $1.31(1.19-1.44)$ & $<0.01$ & 152 & $57 \%$ & $1.35(1.01-1.80)$ & $\mathbf{0 . 0 3}$ \\
\hline $63-73$ & 1,429 & $39 \%$ & $1.07(0.98-1.19)$ & 0.13 & 86 & $47 \%$ & $1.09(0.78-1.54)$ & 0.60 \\
\hline$\geq 74$ & 1,182 & $36 \%$ & 1.00 & & 80 & $43 \%$ & 1.00 & \\
\hline \multicolumn{9}{|c|}{ APFT 2 mile (minutes) (Tertiles) ${ }^{\mathrm{a}}$} \\
\hline$\geq 15.68$ & 1,121 & $50 \%$ & $1.49(1.35-1.65)$ & $<0.01$ & 259 & $53 \%$ & $1.32(0.61-2.85)$ & 0.42 \\
\hline $14.14-15.67$ & 1,351 & $38 \%$ & $1.15(1.04-1.28)$ & $<0.01$ & 19 & $37 \%$ & $0.92(0.35-2.41)$ & 0.87 \\
\hline$\leq 14.13$ & 1,267 & $33 \%$ & 1.00 & & 10 & $40 \%$ & 1.00 & \\
\hline
\end{tabular}

Notes: Boldface indicates statistical significance $(p<0.05)$.

${ }^{\mathrm{a}}$ Tertile categories based on enlisted men and women combined (gender neutral)

APFT, Army Physical Fitness Test 
Table 2. Injury Risk Factors in Army Soldiers

\begin{tabular}{|c|c|c|c|c|c|c|c|}
\hline \multicolumn{5}{|c|}{ Unadjusted Injury Risk } & \multicolumn{3}{|c|}{ Multiple Logistic Regression } \\
\hline Variable level & $\mathbf{N}$ & N (\%) Injury & Risk ratio (95\% CI) & $p$-value & $N$ & OR $(95 \% C I)$ & p-value \\
\hline \multicolumn{8}{|l|}{ Gender } \\
\hline Women & 363 & $191(53 \%)$ & $1.26(1.14-1.40)$ & $<0.01$ & 305 & $0.89(0.67-1.19)$ & 0.44 \\
\hline Men & 4,324 & $1,804(42 \%)$ & 1.00 & & 3,682 & 1.00 & \\
\hline \multicolumn{8}{|l|}{$\operatorname{Age}^{a}$ (years) } \\
\hline $22-26$ & 1,412 & $528(37 \%)$ & 1.00 & & 1,262 & 1.00 & \\
\hline $27-30$ & 1,450 & $626(43 \%)$ & $1.16(1.06-1.26)$ & $<0.01$ & 1,292 & $1.26(1.07-1.48)$ & 0.01 \\
\hline$\geq 31$ & 1,825 & $841(46 \%)$ & $1.23(1.13-1.34)$ & $<0.01$ & 1,433 & $1.28(1.08-1.51)$ & $<0.01$ \\
\hline \multicolumn{8}{|l|}{ Body fat $\%^{\mathrm{b}}$} \\
\hline$\leq 19.28$ & 1,557 & $564(36 \%)$ & 1.00 & & 1,461 & 1.00 & \\
\hline $19.29-23.37$ & 1,557 & $641(41 \%)$ & $1.14(1.04-1.24)$ & $<0.01$ & 1,322 & $1.08(0.92-1.26)$ & 0.36 \\
\hline$\geq 23.38$ & 1,507 & $766(50 \%)$ & $1.40(1.29-1.52)$ & $<0.01$ & 1,204 & $1.30(1.08-1.57)$ & 0.01 \\
\hline \multicolumn{8}{|l|}{ Cigarette smoking $^{\mathrm{c}}$} \\
\hline Non-smoker & 2,517 & $43 \%$ & 1.00 & & & & \\
\hline Smoker & 2,342 & $44 \%$ & $1.04(0.98-1.11)$ & 0.22 & & & \\
\hline \multicolumn{8}{|c|}{ APFT push-ups (reps) $\left(\right.$ Tertiles) ${ }^{\mathrm{b}}$} \\
\hline$\leq 57$ & 1,541 & $728(47 \%)$ & $1.29(1.18-1.41)$ & $<0.01$ & 1,348 & $1.11(0.91-1.34)$ & 0.32 \\
\hline $58-71$ & 1,452 & $598(41 \%)$ & $1.13(1.03-1.24)$ & 0.01 & 1,353 & $1.03(0.86-1.22)$ & 0.76 \\
\hline$\geq 72$ & 1,353 & $495(37 \%)$ & 1.00 & & 1,286 & 1.00 & \\
\hline \multicolumn{8}{|c|}{ APFT sit-ups (reps) (Tertiles) ${ }^{b}$} \\
\hline$\leq 62$ & 1,548 & $749(48 \%)$ & $1.32(1.21-1.45)$ & $<0.01$ & 1,369 & $1.28(1.06-1.55)$ & 0.01 \\
\hline $63-73$ & 1,515 & $598(40 \%)$ & $1.08(0.98-1.19)$ & 0.12 & 1,416 & $1.05(0.88-1.24)$ & 0.61 \\
\hline$\geq 74$ & 1,262 & $462(37 \%)$ & 1.00 & & 1,202 & 1.00 & \\
\hline \multicolumn{8}{|c|}{ APFT 2 mile (minutes) (Tertiles) ${ }^{\mathrm{b}}$} \\
\hline$\geq 15.68$ & 1,380 & $693(50 \%)$ & $1.51(1.37-1.66)$ & $<0.01$ & 1,370 & $1.53(1.26-1.85)$ & $<0.01$ \\
\hline $14.14-15.67$ & 1,370 & $524(38 \%)$ & $1.15(1.04-1.27)$ & 0.01 & 1,352 & $1.06(0.90-1.25)$ & 0.50 \\
\hline$\leq 14.13$ & 1,277 & $425(33 \%)$ & 1.00 & & 1,265 & 1.00 & \\
\hline \multicolumn{8}{|c|}{ Occupational physical demand } \\
\hline Very heavy & 3,534 & $1,494(42 \%)$ & 1.00 & & 2,999 & 1.00 & \\
\hline Moderately heavy & 692 & $313(45 \%)$ & $1.07(0.98-1.17)$ & 0.15 & 563 & $0.97(0.81-1.17)$ & 0.77 \\
\hline Heavy & 422 & $201(48 \%)$ & $1.13(1.01-1.25)$ & 0.04 & 336 & $1.08(0.85-1.37)$ & 0.52 \\
\hline
\end{tabular}




\begin{tabular}{l} 
Medium/Light $122 \quad 52(43 \%) \quad 1.01(0.82-1.24)$ \\
\hline Notes: Boldface indicates statistical significance $(p<0.05)$. \\
${ }^{\mathrm{a}}$ No Soldiers under age of 22. \\
${ }^{\mathrm{b}}$ Tertile categories based on both enlisted men and women combined. \\
${ }^{\mathrm{c}}$ Variable was not significant and was not interested into multiple logistic regression model \\
APFT, Army Physical Fitness Tests
\end{tabular}




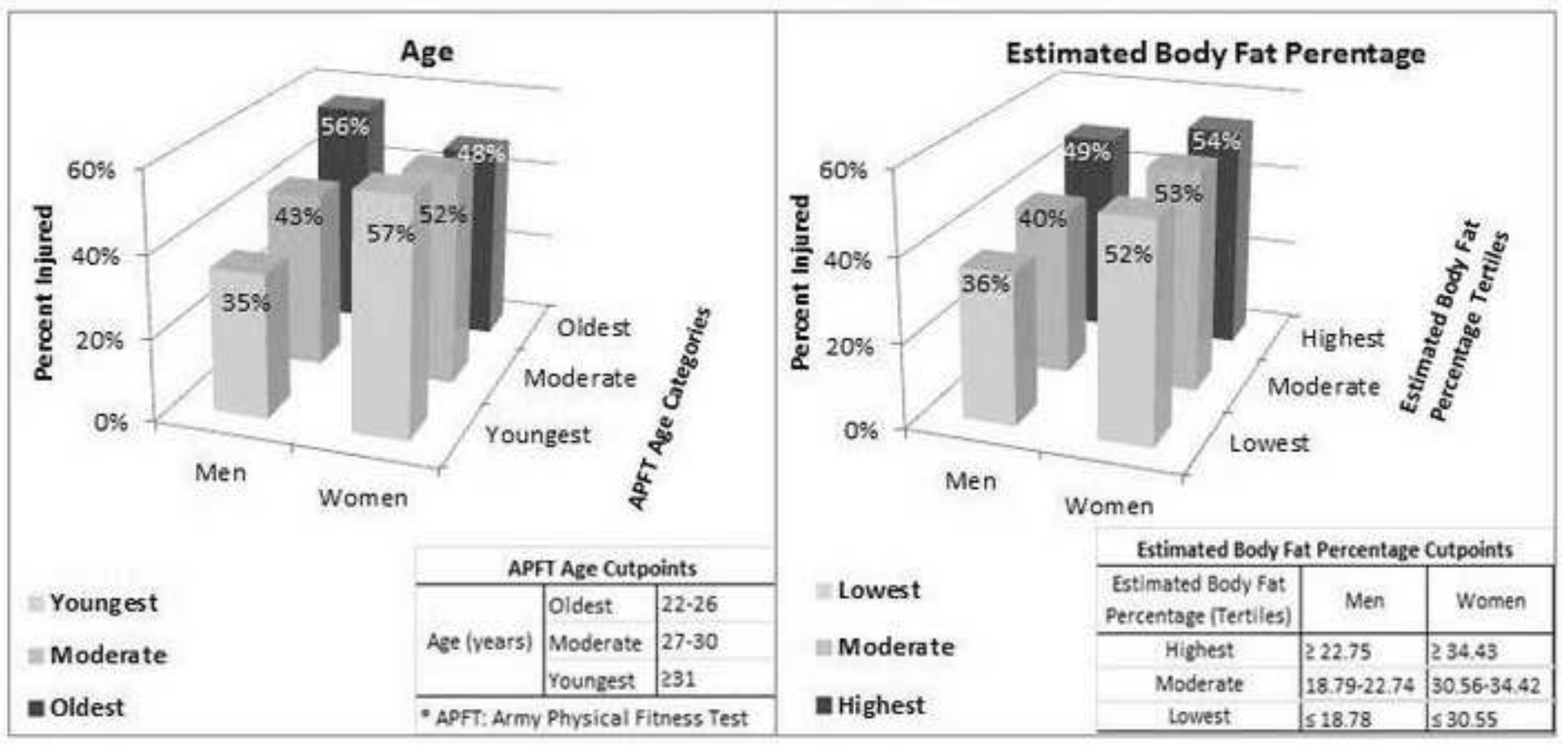



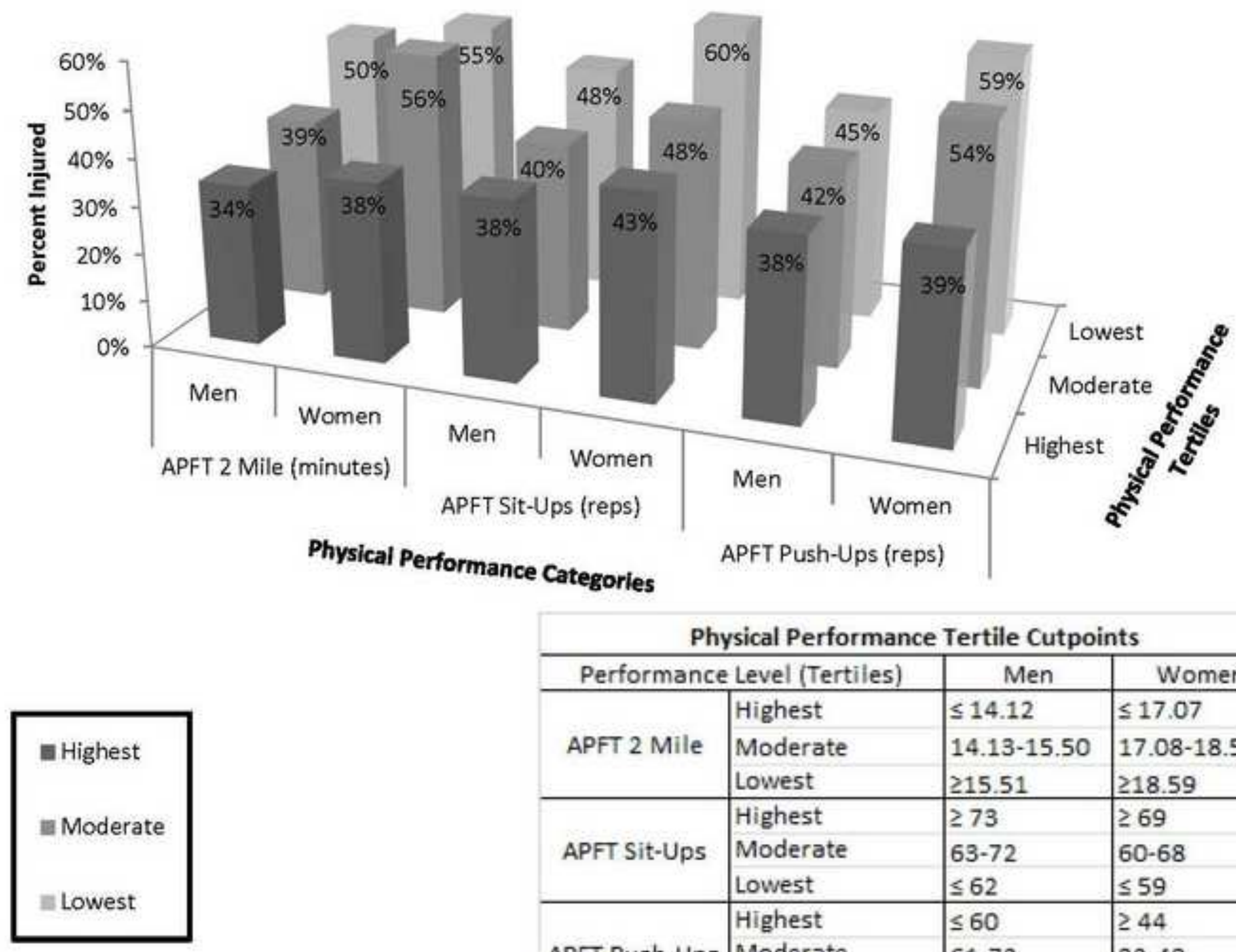

\begin{tabular}{|c|c|c|c|}
\hline \multicolumn{4}{|c|}{ Physical Performance Tertile Cutpoints } \\
\hline \multicolumn{2}{|c|}{ Performance Level (Tertiles) } & Men & Women \\
\hline \multirow{3}{*}{ APFT 2 Mile } & Highest & $\leq 14.12$ & $\leq 17.07$ \\
\hline & Moderate & $14.13-15.50$ & $17.08-18.58$ \\
\hline & Lowest & 215.51 & 218.59 \\
\hline \multirow{3}{*}{ APFT Sit-Ups } & Highest & $\geq 73$ & $\geq 69$ \\
\hline & Moderate & $63-72$ & $60-68$ \\
\hline & Lowest & $\leq 62$ & $\leq 59$ \\
\hline \multirow{3}{*}{ APFT Push-Ups } & Highest & $\leq 60$ & $\geq 44$ \\
\hline & Moderate & $61-72$ & $32-43$ \\
\hline & Lowest & $\geq 73$ & $\leq 31$ \\
\hline
\end{tabular}

